\title{
MAGNITUD DE LA ECONOMÍA INFORMAL EN EL PERÚ Y EL MUNDO
}

PAULINO BARRAGÁN ARQUE*

E-mail: pbarragaesunat.gob.pe

\section{RES UMEN}

En el Perú, el crecimiento de la economía informal está asociado al crecimiento de la población, al escaso crecimiento de la economía y a la escasez de fuentes de trabajo. Se calcula que la economía informal en nuestro país es equivalente al 35\% del PBI y al 60\% de las horas hombre trabajadas; es decir, un 35\% de la producción y un 60\% del trabajo.

La economía informal no es un fenómeno exclusivo de los países en vías de desarrollo; hoy en día, la globalización de la economía ha evidenciado que la práctica de producir riqueza y crear empleo fuera del marco legal es también un fenómeno del mundo desarrollado.

La magnitud de la economía informal en los países en vías de desarrollo y en los países desarrollados no aparece en las estadísticas oficiales de las Cuentas Nacionales, por lo que se desconoce con exactitud su medición e incidencia en la economía nacional; lo que constituye una gran limitación en el diseño de la política económica, la política fiscal y la política tributaria en su conjunto.

Palabras clave: Economía informal, subterránea, paralela, negra.

\section{ABSTRACT}

In Peru the growth of the informal economy is associated to the population's growth, the scarce growth of the economy and the shortage of work sources. It is calculated that the informal economy in our country is equivalent to $35 \%$ of the PBI and $60 \%$ of work.

The informal economy is not an exclusive phenomenon of the developing countries. Today the globalization of the economy has evidenced that the practice of producing wealth and creating employment outside of the legal context is also a phenomenon of the developed world.

The magnitude of the informal economy in the developing countries and in the developed countries doesn't appear in the official statistics of the Bills, for what it is ignored with accuracy its measure and incidence on the National Economy, what constitutes a great limitation in the design of the economical policies, the fiscal policies and the tributary policies altogether.

Keywords: Black and parallel, subway, informal economy.

* Contador Público Colegiado, Profesor Asociado de la Universidad Nacional Mayor de San Marcos y Secretario Técnico de la Comisión Supervisora de los Créditos Tributarios Financieros del Estado - Ministerio de Economía y Finanzas. 


\section{INTRODUCCIÓN}

La economía informal, economía subterránea, economía paralela o simplemente economía negra, es el sector de la economía que no aparece en las estadísticas oficiales de las Cuentas Nacionales, por lo que se desconoce con exactitud su medición e incidencia en el desenvolvimiento de la Economía Nacional. Esto constituye una gran limitación en el diseño de lapolítica económica, la política fiscal y la política tributaria en su conjunto, porque dificulta sustancialmente las decisiones que toma el gobierno a nivel macroeconómico, y hace que en algunos casos tales decisiones sean excesivamente especulativas, produciéndose entre otros efectos negativos, evasión fiscal, déficite inflación.

La economía informal, parecía ser un fenómeno exclusivo de los países en vías de desarrollo o de algunos países avanzados de naturaleza peculiar como Italia, donde fue siempre una actividad importante, pero hoy en día, la globalización de la economía ha contagiado también al mundo desarrollado en la práctica de producir riqueza y crear empleo fuera del marco legal, tal como se analizará más adelante.

En el Perú, la economía informal no es un fenómeno nuevo. Su crecimiento está asociado al crecimiento de la población y al escaso crecimiento de la economía, pues en el sector formal no se generan los empleos que la gente demanda. En situaciones de crisis, la economía informal tiende a incrementarse porque la escasez de fuentes de trabajo obliga a las personas a emplearse en actividades no reguladas.

En términos generales, se calcula que la economía informal en nuestro país es el equivalente a un 35\% del PBI y un 60\% de las horashombre trabajadas se desarrollan en las actividades informales. Es decir, un 35\% de la producción y un 60\% del trabajo.

Desde la perspectiva institucional, se entiende a la informalidad como:

«una manifestación de la incapacidad del gobierno de generar reglas de juego en el ámbito económico que faciliten las transacciones económicas, reduzcan los costos de información y transacción, y garanticen el derecho a la propiedad ${ }^{1}$.

Esto puede percibirse en nuestra realidad cotidiana en distintos aspectos: regulaciones y controles que dan amplio espacio a la discrecionalidad y que entorpecen a la actividad económica, e igualmente en la incapacidad gubernamental para hacer cumplir la ley. Estos elementos son estímulos para una informalidad creciente; hay leyes, reglamentos y trámites que obstaculizan a quienes quieren emprender un negocio por la vía plenamente legal.

No obstante los radicales cambios económicos causados por la crisis económica de la década del ochenta y las privatizaciones de las empresas públicas de los años noventa, aún continúan siendo muy altos los costos para cumplir con reglamentos y regulaciones. Esos costos están ubicados en tres zonas claves: el mercado laboral, la estructura fiscal y en la normatividad para el establecimiento y operación de negocios.

\section{ALgUNAS CAUSAS DEL CRECIMIENTO DE LA ECONOMÍA INFORMAL}

- La expansión de la economía informal se vio favorecida en las décadas de los 80 y 90, por las políticas de ajuste estructural y de estabilización económica que en muchos países produjeron el crecimiento de la pobreza, el desempleo y el subempleo. La crisis financiera asiática de mitad de los noventa provocó un crecimiento acelerado de las actividades económicas marginales.

- Un reciente caso de expansión del trabajo informal es Argentina. Luego de más de una década de aplicación de las recetas del FMI, privatizaciones y rampante corrupción, la mitad de la población económicamente activa está sin empleo o tiene problemas en el trabajo. Unos 3.5 millones de argentinos están desocupados y otro tanto hace trabajos precarios o temporales que no cubren el mínimo de horas semanales indispensables para la subsistencia.

- La pobreza es uno de los factores del crecimiento de la economía informal.

«Es la pobreza la que fuerza a la mayoría de las personas a aceptar puestos de trabajo poco atractivos en la economía informal. Los bajos ingresos que se obtienen de estos empleos crean un círculo vicioso de pobreza» ${ }^{2}$.

Sin embargo, trabajo informal no siempre equivale a pobreza. Existen trabajadores informales, especialmente aquellos que laboran por cuenta propia, que ganan más que los trabajadores poco calificados del sector 
formal. Pero esta es la excepción: la economía informal concentra a los trabajadores más pobres, especialmente de las zonas rurales.

- Más allá de la distinción del trabajo formal o informal, el déficit de trabajo decente caracteriza a la economía globalizada. Al comenzar el presente decenio, 160 millones no tienen empleo y un tercio de los 3000 millones de trabajadores que hay en el mundo están desempleados, subempleados o con ingresos insuficientes para mantener a sus familias.

- Según el estudio de la OIT, el crecimiento de la economía informal en los países en desarrollo está ligado a factores demográficos como el exceso de mano de obra, de ahí que sea importante tener en cuenta las corrientes migratorias del campo a la ciudad, las migraciones internacionales y la creciente incursión de la mujer en las actividades económicas.

«Ya sea por elección o necesidad, más y más mujeres entran en el mercado laboral, pero muy a menudo acaban en trabajos situados en lo más bajo de la economía informal, debido a que suelen tener peor preparación en términos de educación y formación, tienen menos acceso a los recursos, aún debe hacer frente a diversas formas directas e indirectas de discriminación y soportan la carga de las responsabilidades familiares» ${ }^{3}$.

- El crecimiento del sector de «tecnología de punta» y la consiguiente demanda de personal altamente especializado relega a las personas no cualificadas que buscan trabajo en la economía informal. Por otro lado, los salarios del sector público en muchos países en desarrollo son insuficientes para mantener una familia, por lo que los empleados 0 sus cónyuges se ven obligados a buscar ocupación en la economía informal.

- La vigencia de un régimen impositivo depredador de las actividades empresariales y profesionales, o un sistema de subsidios de jubilación, enfermedad, invalidez, que estimula el fraude.

- La vigencia de un modelo de crecimiento económico «sin empleo» ha agudizado el trabajo informal. En este contexto, se han implementado políticas que tienden a favorecer a la inversión extranjera, así como a las grandes empresas manufactureras, descuidando el sector agrícola del que dependen la mayoría de habitantes de los países del sur.
- Por último, la mayoría de las personas ingresa a la economía informal porque no puede encontrar empleo en la economía formal y tampoco puede permitirse el desempleo absoluto. La cantidad de trabajadores informales es amplia: incluye a vendedores ambulantes, lustrabotas, recolectores de basura, chatarreros y traperos; trabajadores domésticos, trabajadores a domicilio, trabajadores de fabricas, trabajadores independientes de microempresas y otros.

\section{LA MAGNITUD DE LA ECONOMÍA INFORMAI EN EL PERÚ}

En nuestro país, la informalidad no se origina en una tara cultural, en un problema religioso o en un origen étnico; se encuentra en la ineficiencia de la ley. En términos técnicos, somos informales por el llamado coste de la legalidad. Los políticos, los legisladores y los abogados, no entienden que la ley cuesta como cualquier otra cosa. Si usted quiere hacer un negocio, necesita tiempo e información. Hacer el negocio cuesta algo independientemente del negocio mismo. Vender pintura cuesta algo más que la pintura misma; cuesta la oportunidad, la inteligencia, la ubicación, la percepción del deseo de los consumidores, igual la ley. La ley cuesta con independencia de lo que se quiera hacer con ella. ¿Cuál es el costo de la ley, entonces? La cantidad de tiempo y de información que se necesita para cumplir con ella.

\subsection{LA CONSTRUCCIÓN INFORMAL}

El desarrollo urbano en el Perú se ha hecho fundamentalmente en el sector informal. La mayor parte de Lima (más de 9 millones de habitantes), aproximadamente la mitad de su área geográfica, se encuentra desarrollada en los denominamos eufemísticamente «pueblos jóvenes, » que no son otra cosa que las barriadas urbano-marginales, asentamientos humanos desarrollados por invasión de terrenos públicos o privados por parte de migrantes del campo a la ciudad de los últimos 45 años.

El desarrollo de este sector informal tiene gran importancia económica, social y política en nuestro país. En primer lugar, es económicamente significativo porque la inversión realizada por la gente equivale aproximadamente a $8000 \mathrm{u}$ 8500 millones de dólares; inversión de 
viviendas que se ha realizado sin ningún tipo de apoyo por parte del Estado.

En segundo lugar, es socialmente importante porque representa la emergencia de un nuevo sector propietario. Tradicionalmente en el Perú, los sectores menos favorecidos han estado ausentes de la propiedad, y su acceso ha estado limitado a los sectores ricos o aristocráticos. A través de este proceso de urbanización informal, los sectores menos favorecidos han logrado reivindicar para sí el derecho a la propiedad. En ese sentido, la construcción informal ha tenido una significación política muy notable, porque, en última instancia, solo la gente que es propietaria lucha por algo. Solo cuando se tiene algo se tiene sentido de la responsabilidad, de la lucha y del desafío político.

Los países donde no existen muchos propietarios son países donde la sociedad es débil, donde la ciudadanía no se enfrenta al poder político porque hay muy poco espacio para el desarrollo individual.

\subsection{EL COMERCIO INFORMAL}

El comercio informal es una las actividades más notables de la economía informal en el Perú. Se lleva a cabo fundamentalmente a través del comercio callejero -los llamados vendedores ambulantes o buhoneros- que existen en todas las ciudades de América Latina. Mucha gente de origen humilde, probablemente migrantes del campo a la ciudad que, dada la situación en la que se encuentran, tiene que dedicarse a comerciar para así generar una actividad empresarial que les permita ganar una subsistencia mínima.

Aunque no se cuenta con un censo actualizado, se calcula que en el año 90 ó 91 había aproximadamente 300000 vendedores ambulantes en Lima. A raíz de los programas de ajuste económico llevados a cabo por el gobierno, esta cantidad creció significativamente. De hecho, más medio millón de empleados públicos fueron despedidos por el gobierno peruano, y muchos de ellos encontraron refugio en el sector comercial informal.

La importancia social de los ambulantes emana de su reivindicación de la empresa privada para los sectores menos favorecidos de la sociedad peruana. Por lo general, hemos leído libros y hemos escuchado programas en la radio y en la televisión que nos han tratado de convencer que el capitalismo es una cosa ajena en el Perú y América Latina; que quienes somos empresarios en el Perú formamos una vanguardia de la penetración extranjera o un rezago de la aristocracia colombina, pero que no somos auténticos peruanos, mexicanos, y, ni siquiera, capitalistas porque no representamos al capitalismo. ¡Esto es mentira! Y para probar esta mentira, no hay que escribir libros de texto ni citar a Adam Smith. Para demostrar que es mentira basta con salir a las calles de cualquier ciudad de Latinoamérica y enseñarles a aquellos que se resisten a aceptar la evidencia que los pobres latinoamericanos ejercen el capitalismo en las mismas calles aunque nadie se lo haya enseñado; que no tienen que ser ricos para ser empresarios, solamente les basta ser trabajadores; que no tienen que ser listos para ganar dinero, solamente les basta ser ordenados; que no tienen que ser sabios para descubrir una oportunidad, solamente les basta ser audaces. Con la decisión, con la honestidad y con la audacia, las calles del Perú se han convertido en la mejor escuela de empresarios que existe.

Es más, la existencia de este sector comercial informal nos ofrece el mejor argumento disponible para convencer a aquella gente que tiene la reclusión ideológica de negar que el trabajo y la responsabilidad son virtudes inherentes al ser humano.

\subsection{LA INDUSTRIA INFORMAL}

Al igual que en el comercio, la presencia de la informalidad en la industria es también significativa. El industrial informal es de dos tipos en el Perú. Uno es el propio industrial formal que informaliza parte de su producción como consecuencia del alto coste de la regulación o de los impuestos. Aunque esconda parte de su facturación, no es una persona diferente al industrial ya establecido. En muchos casos se ha visto obligado a hacerlo porque el coste de la legalidad es muy alto. Tiene así que abandonar la formalidad para ocultarse total o parcialmente en el mercado informal. Esto se produce siempre que hay un alza de precios o siempre que aumenta la inflación, que es una forma indirecta de subir los impuestos.

Pero hay también otro tipo de informales en el sector industrial que son los artesanos o los industriales propiamente informales, que se dedican de una manera completamente ilegal al 
desarrollo de alguna actividad manufacturera. En nuestro país, esta actividad es más pronunciada y se manifiesta en las confecciones y los textiles, la fabricación de muebles de madera, y el área de la mecánica. Son tres áreas donde existe una gran cantidad de actividades de tipo informal. Por ejemplo, en el área artesanal, hay gente que en la intimidad y en la seguridad de su vivienda montan un pequeño taller con familiares o paisanos, a los cuales inclusive muchas veces no les pagan o les pagan de manera indirecta enseñándoles el oficio. De esa forma, se genera una actividad microempresarial significativa.

\subsection{LOS SERVICIOS INFORMALES}

En el Perú, el nivel de actividad de los servicios informales es bastante alto. El más notable es el servicio del transporte. En los países desarrollados, el transporte público es generalmente estatal; en los países subdesarrollados, el transporte público es generalmente privado e informal. Alrededor de América Latina, la emergencia de grandes ciudades ha ido emparejada con el desarrollo de grandes sistemas de transporte informal.

En 1990, el 95\% del transporte urbano del Perú estaba en manos de pequeños empresarios, cada uno dueño de su ómnibus o de su combi. En ese mismo año, el cien por ciento del transporte urbano público se fue a la quiebra. El gobierno peruano disolvió la única empresa pública que existía en el transporte urbano al venderle a cada uno de los conductores su carro, informalizando así por completo la actividad del transporte urbano. También en 1990 el Alcalde de Lima liberalizó el transporte urbano al declarar la libertad absoluta de rutas, de tarifas, y de entrada y salida. Esto obligó a los conductores de taxis a tener una gran imaginación ya que, como empresarios que son, tienen que identificar el deseo del viajero y ofrecer servicios diferenciados.

La libertad de tarifas también ha producido el fenómeno siguiente: hay todo tipo de servicios y a todo precio. Si usted quiere ir apachurrado como en una lata de sardinas, paga un precio bajo. Si, por el contrario, quiere ir cómodamente sentado en un vehículo con aire acondicionado y televisor tiene que pagar un precio distinto. Inclusive hay un servicio especial nonstop entre un punto y otro, de tal manera que ese es otro tipo de servicio y a otro pre- cio. Todo esto ha sido generado informalmente tanto en los vehículos de alquiler, los taxis, como en los vehículos de transporte masivo.

Mucha gente cree que casualmente esta ha sido la clave por la cual el gobierno de la década de los 90 no ha confrontado ni un solo acto de rechazo de su política económica en diez años, pese a haber hecho el ajuste económico más dramático y profundo de América Latina, porque todos los despedidos encontraron algo más ventajoso que hacer.

La paradoja fue la siguiente:

La gente que salió del sector público como consecuencia de los ajustes económicos, en total, entre 500 y $600 \mathrm{mil}$ personas, inmediatamente comenzó a trabajar en el sector privado, muchos de ellos dentro del servicio de transportes. Sus ingresos en ese sector eran mucho más altos, ya que los sueldos durante un proceso inflacionista como el que padeció el Perú (un millón por ciento de inflación durante los cinco años del gobierno de Alan García) eran mínimos -10 dólares, 20 dólares, 30 dólares, 50 dólares en el mejor de los casos en el sector público-. En cambio, como transportistas privados, ganaban tres o cuatro mil dólares mensuales ${ }^{4}$.

\subsection{COMENTARIOS ADICIONALES SOBRE LA ECONOMÍA INFORMAL EN EL PERÚ}

Como hemos visto, hay informalidad en todo; en la vivienda, el comercio, la industria, los servicios de transporte, etc. De hecho, si el $60 \%$ del trabajo de los peruanos se desarrolla en el mercado informal, es porque una parte de su trabajo se desarrolla formalmente y otra parte se desarrolla informalmente. Por ejemplo, el caso del empleado bancario que tiene un vehículo: de ida al trabajo y de regreso del mismo, trabaja como taxista para suplementar su ingreso personal. Es el caso de la señora que después de dejar a los niños en el colegio hace pasteles y dulces para venderlos a restaurantes de la ciudad. También es el caso de la señora que usa el garaje de su casa y lo convierte en un pequeño restaurante. Esto son los casos de los peruanos que reivindican permanentemente su derecho a trabajar con prescindencia del Estado, sin pagar impuestos, y sin obedecer sus regulaciones.

En el Perú, al igual que en otros países de América Latina, la cantidad de tiempo y de infor- 
mación, y los costos que se necesitan para cumplir con la ley son muy altos, de hecho comparativamente más alto de lo que se necesita en Estados Unidos para cumplir con la ley. La diferencia entre países desarrollados y subdesarrollados ${ }^{5}$ está en la organización institucional eficiente; es decir, en el coste de la ley. Un país próspero tiene un coste de la ley bajo en comparación con los ingresos de la población; un país que no es próspero tiene un coste de la ley alto en comparación con los ingresos de la población.

En el Perú, donde tenemos evidencia factible, la ley es tan costosa que distorsiona al mercado y excluye de él a los sectores menos favorecidos de la población; la gente de pocos ingresos no puede cumplir con la ley, no puede pagar los impuestos, no puede acceder a una urbanización formalmente construida porque los trámites de hacerlo son inalcanzables. Esta es la realidad objetiva. No es una tara cultural, no es un problema mental, no es una herencia étnica. Es discriminación legal.

El origen de esa discriminación legal radica en ese capitalismo antidemocrático que es el mercantilismo. Lo que subsiste prioritariamente en los países latinoamericanos es un capitalismo en el cual la propiedad privada no es un derecho sino un privilegio y la competencia no existe; el Estado grande e inútil por una parte, y la hipocresía, por otra. Esta generalización de la hipocresía que permite mantener un sistema de privilegio en América Latina puede considerarse sin lugar a dudas la causa principal de nuestro subdesarrollo y de nuestra crisis.

\subsection{LA ECONOMÍA INFORMAL Y LA EVASIÓN TRIBUTARIA EN EL PERÚ}

La economía informal y la evasión tributaría se relacionan recíprocamente tanto en sus causas como en sus efectos. Hernando de Soto en su obra el otro Sendero señala:

«El incumplimiento de las obligaciones directas y las leyes laborales es una de las diferencias, entre formales e informales; los empresarios formales pagan sus impuestos y lo hacen por ellos y por los que no pagan; los empresarios informales que evaden sus obligaciones tributarias producen como efecto que la carga tributaria se haga más pesada para aquellos que cumplen con sus impuestos».

"Se monta un circulo vicioso: como la recaudación es insuficiente, el Estado debe incrementarlo por medio de sucesivos aumentos de impuestos que inciden sobre aquellos que cumplen sus obligaciones fiscales, la presión individual se torna tan alta que dichos contribuyentes comienzan a evadir ingresando de ese modo a las filas de los informales ${ }^{6} »$.

Para tratar de resolver este problema, la SUNAT desde el mes de marzo de 1991, investigó la naturaleza y la magnitud del fenómeno; analizó y estudió la informalidad por sectores y ramas de la actividad productiva, propiciando la Simplificación del Sistema Tributario Nacional y la creación del Régimen Único Simplificado (RUS), mediante el Decreto Legislativo N ${ }^{\circ} 771$ vigente a partir del $1^{\circ}$ de enero de 1994.

Dicho sistema estuvo diseñado para cumplir un fin específico: la simplificación, entendida como un conjunto de normas fáciles de entender para el contribuyente y de fácil administración para la Administración Tributaria bajo los principios de neutralidad, equilibrio, equidad y recaudación.

En ese sentido, el RUS fue creado con el objetivo y la finalidad de ampliar la base tributaria incorporando a la formalidad a las personas naturales y sucesiones indivisas domiciliadas dedicadas a pequeños negocios en la economía informal, quienes mediante un único pago mensual dan por cumplidas sus obligaciones tributarias referidas al Impuesto a la Renta e Impuesto General a las Ventas (IGV), sin necesidad de requerirse la presentación de declaraciones juradas, ni el registro formal de libros de contabilidad.

Posteriormente se incluyó dentro de dicho régimen a las personas naturales no profesionales que exclusivamente obtienen rentas de cuarta categoría; además se efectuaron diversas modificaciones que luego fueron agrupadas en un Texto Único Ordenado de la Ley del RUS, que fue aprobado por Decreto Supremo N. ${ }^{\circ}$ 057-99-EF.

Después de diez años de vigencia de dicho régimen se han introducido importantes modificaciones mediante el Decreto Legislativo N. ${ }^{9} 937$, las mismas que están vigentes desde el primero de enero del año 2004.

- Ventajas. Asegura un flujo de recaudación mínima y estable de contribuyentes de menor capacidad contributiva; disminuye la brecha de inscripción dentro del segmento de pequeños contribuyentes (trámites de 
inscripción sencillos, rápidos y de bajo costo) ; simplifica la fiscalización de la Administración Tributaria porque se determina fácilmente la deuda tributaria; disminuye los costos de captura, digitación y comisión de los bancos de la red bancaria debido a que los pagos mensuales son definitivos; previene la evasión tributaria al prohibir la emisión de comprobantes que sustentan crédito fiscal o costo y/o gasto para efectos tributarios.

- Dificultades. Se ha detectado que los contribuyentes del Régimen General buscan utilizar el RUS como herramienta de evasión y elusión, lo que ha obligado a la Administración Tributaria a controlar el acceso e ir modificando las normas tributarias para evitar nuevas formas elusivas. La Administración no puede utilizar herramientas contables para determinar los ingresos reales de los sujetos acogidos, dado que no existe obligación de llevar contabilidad; este hecho dificulta a veces la detección de la evasión tributaria y las bajas cuotas de pago o su falta de actualización periódica podrían convertirlo en un sistema tributario costoso de administrar.

Se ha detectado también que la mayor parte de los 350000 contribuyentes acogidos al antiguo RUS estaban ubicados en la categoría donde se efectuaba el menor pago (cuarta categoría, A, cuota de S/. 20.00) cuando en realidad se han verificado movimientos comerciales en compras y ventas superiores a la categoría en la que estaban ubicados y que en otros casos superaban el límite mensual de S/.18 000 de ingresos brutos por sus ventas o servicios.

Se ha verificado así mismo que muchas empresas han optado por la modalidad de dividir físicamente su negocio con la finalidad de evitar las obligaciones y cargas propias de los contribuyentes de rentas de tercera categoría del Régimen General y beneficiarse además con la escasa fiscalización realizada a los contribuyentes del RUS.

\section{MAGNITUD DE LA ECONOMÍA INFORMAL EN EL MUNDO}

Definitivamente, la economía informal no es un fenómeno exclusivo de los países subdesarrollados; la globalización de la economía nos muestra que también en el mundo desarrollado esta actividad está muy extendida, tal como lo precisa el economista austríaco Dr. Friedrich Schneider ${ }^{7}$, en la revista The Economist USA, quien estima que el tamaño de la economía informal en el mundo alcanza un volumen de 9 trillones de dólares en traducción literal del inglés, pero en buen español serían 9 billones.

El tamaño oficial de la economía mundial es de US\$ 39 billones y el de la economía de Estados Unidos es de US\$ 9 billones, por lo que la informalidad mundial añade otra economía equivalente a la de Estados Unidos. Eso nos da una idea de su magnitud.

El Dr. Schneider estudió la economía informal en 76 naciones, tanto industrializadas como emergentes. Basándose en esa investigación la revista The Economist estima que en los países ricos la economía informal fluctúa alrededor del 15\% del PBI, y que en los países en desarrollo alcanza más del 33\% del PBI.

De los 76 países examinados, Nigeria, Tailandia y Egipto tienen las economías informales más grandes, sobrepasando el 70\% de PBI. Al otro extremo, el país con la economía informal más pequeña es Suiza, con apenas $10 \%$ del PBI. Es interesante notar que donde más se respeta el secreto bancario, menos informalidad hay. A Suiza la siguen Japón, Estados Unidos y Austria.

Pero en Europa la situación se deteriora en vez de mejorar. La economía informal alemana equivale al $20 \%$ del PBI y $22 \%$ de su gente trabaja en la economía informal, cuando en 1970 era solo el 10\%. Mientras más altos son los impuestos y más entrometidas las regulaciones gubernamentales, mayor es el incentivo a operar en la informalidad. Así vemos que en Italia, España y Bélgica, la informalidad fluctúa entre 23\% y 28\% del PBI.

En Italia y Bélgica el peso total de los impuestos, sumando los impuestos a las ventas, a la renta y las contribuciones por nómina a la seguridad social, sobrepasa el 70\% del ingreso del trabajador. Esto se compara con el 41\% de Estados Unidos (ver anexo).

Mucho más extendida es la informalidad en América Latina, donde la mayoría de la gente simplemente no puede pagar el alto costo de la legalidad. Cuando una persona quiere establecer su propio negocio, necesita contratar los servicios de un abogado y luego dedicar semanas, si no meses, a conseguir permisos y 
licencias en una multitud de oficinas públicas diferentes, además de tener que pagar bajo la mesa a una infinidad de funcionarios corruptos para «agilizar» la tramitación.

La magistral obra de Hernando de Soto, El otro sendero ${ }^{8}$, publicado en 1986, señalaba que la economía informal del Perú alcanzaba entonces $60 \%$ de las horas-hombre trabajadas. En Venezuela, desde hace varios años, más del 50\% de la población trabaja informalmente. Se trata de dos países ricos en recursos naturales donde sus malos gobiernos han construido tan absurdos obstáculos al trabajo que un altísimo porcentaje de la ciudadanía no tiene más recurso que vivir y trabajar al margen de la ley.

Por el contrario, como lo mostró el periodista de $A B C$ John Stossel, en su programa de televisión «20/20» en setiembre de este año, en Hong Kong él mismo logró abrir una tienda en un centro comercial en menos de 24 horas. Eso, en gran parte, explica la riqueza de inmigrantes que llegaron de la China con sólo la ropa que traían puesta, pero con trabajo y sin obstáculos oficiales transformaron una roca sin más recursos naturales que un buen puerto, en la ciudad más próspera y con mayor densidad del mundo, todo ello en una sola generación. Ello también comprueba que el llamado «exceso» de población, si llega a ser un problema, es insignificante comparado con el exceso de impuestos, regulaciones y malas leyes.

\section{CONCLUSIONES}

1. Desde la década de los años 80 y 90, el Perú vive una revolución de los informales los mismos que han reivindicado para sí el derecho a la propiedad privada, el derecho a la empresa, y, sobre todo, la capacidad y el esfuerzo individual.

2. Al reivindicar estos derechos, los menos favorecidos se han convertido en la vanguardia de la construcción de una auténtica economía de mercado, del auténtico sector empresarial de origen popular, y han creado una base fundamental para ser optimistas con el cambio.

3. Hernando de Soto sostiene que en el Perú el problema no está en la economía informal sino en el Estado. «Aquella es, más bien, una respuesta popular espontánea y creativa ante la incapacidad estatal para satisfacer las aspiraciones más elementales de los pobres.
Cuando la legalidad es un privilegio al que solo se accede mediante el poder económico y político, a las clases populares no les queda otra alternativa que la ilegalidad». Este es el origen del nacimiento de la economía informal que Hernando de Soto documenta con pruebas incontrovertibles.

4. La economía informal-sociedad paralela es en muchos sentidos, más autentica, trabajadora y creativa que la que usurpa el título de país legal y aparece como una puerta de salida del subdesarrollo que ya ha comenzado a franquear resueltamente a muchas de sus víctimas, en un proceso que está revolucionando desde su raíz la economía de la nación, sin que curiosamente, parezcan advertirlo la gran mayoría de quienes escriben y teorizan sobre el atraso y las inquietudes sociales del tercer mundo.

5. La informalidad es una réplica de las mayorías contra ese sistema que las ha hecho tradicionalmente víctimas de una suerte de apartheid económico y legal. En ese sistema, las leyes parecerían pensadas para cerrarles el acceso a cosas tan elementales como tener un trabajo y disponer de un techo. ¿Iban a renunciar a estas aspiraciones básicas de supervivencia en nombre de una legalidad en muchos sentidos irreal e injusta? Renunciaron, más bien, a la legalidad, y salieron a las calles a vender lo que podían, montaron sus talleres de fortuna y armaron sus viviendas en los cerros y arenales. Como no había trabajo, lo inventaron, aprendiendo sobre la marcha lo mucho que no sabían y haciendo del defecto virtud, administraron con sabiduría su ignorancia9.

6. De emigrantes a informales. Así fue, de esta manera que, para subsistir, los migrantes se convirtieron en informales. Para vivir, comerciar, manufacturar, transportar y hasta consumir, los nuevos habitantes de la ciudad tuvieron que recurrir al expediente de hacerlo ilegalmente. Pero no a través de una ilegalidad con fines antisociales como en el caso del narcótico, el robo o el secuestro, sino utilizando medios ilegales para satisfacer objetivos esencialmente legales, como construir una casa, prestar un servicio o desarrollar una industria.

7. Podríamos decir que la informalidad se produce cuando el derecho impone reglas que exceden el marco normativo socialmente aceptado, no ampara las expectativas, elecciones y 
preferencias de quien no puede cumplir tales reglas y el Estado no tiene la capacidad coercitiva suficiente. No son informales los individuos, sino sus hechos y actividades. A medida que los informales han avanzado, el Estado peruano se ha ido replegando, considerando cada concesión como temporal, «hasta salir de la crisis», cuando en realidad no es otra cosa que adoptar de mala gana una estrategia de retirada permanente. Retirada que paso a paso, socava su vigencia social.

\section{NOTAS}

Ball, Carlos. La economía Informal. AIPE - Venezuela.

2 Organización Internacional del Trabajo - OIT. Trabajo Decente y Economía Informal. Reunión, 2002.

3 OIT. Geografía del Trabajo Informal.

4 Ghersi, Enrique. La Economía Informal en América Latina. CATO.

North, Douglass C. Premio Nóbel de Economía en 1994.

6 De Soto, Hernando. El Otro Sendero - La Revolución Informal.

7 Kepler-Linz, Profesor Austríaco.

8 De Soto, Hernando; Ghersi, Enrique y Ghibellini, Mario. El otro sendero.

9 Beaumont Callirgos, Ricardo Arturo. El sector informal y el derecho.

\section{BIBLIOGRAFÍA}

De Soto, Hernando; Ghersi, Enrique y Ghibellini, Mario. El otro Sendero - La Revolución Informal. Instituto Libertad y Democracia.

Ghersi, E. La Economía Informal en América Latina. CATO - Instituto de Desarrollo Económico.

Organización Internacional del Trabajo (OIT) . Trabajo Decente y Economía Informal. 90 Reunión 2002 - Conferencia Internacional del Trabajo.

Ball, C. La Economía Informal. AIPE. Venezuela.

Vargas Llosa, M. El desquite de los pobres. En: Caretas, 1997.

Beaumont Callirgos, R. A. El Sector Informal y el Derecho

Decreto Legislativo N. ${ }^{\circ} 771$. Ley Marco del Sistema Tributario Nacional.

Decreto Legislativo N. 937 . Nuevo Régimen Único Simplificado.

Morote, H. Réquiem por el Perú - Mi patria. 